\title{
Targets of $17 \beta$-oestradiol-induced apoptosis in colon cancer cells: a mechanism for the protective effects of hormone replacement therapy?
}

\author{
Yan Qiu, Michael J S Langman and Margaret C Eggo \\ Division of Medical Sciences, The Medical School, University of Birmingham, Edgbaston, Birmingham B15 2TT, UK \\ (Requests for offprints should be addressed to M C Eggo; Email: M.C.Eggo@bham.ac.uk)
}

\begin{abstract}
Epidemiological studies show a strong link between postmenopausal hormone replacement therapy and decreased incidence of colorectal cancer. The colon cancer cell line, COLO 205 , develops sensitivity to $17 \beta$-oestradiol $\left(E_{2}\right)$ in apoptosis assays with increasing passage number $(>40)$, and we hypothesised that genes selectively regulated in multiply passaged cells were likely to be important in $\mathrm{E}_{2}$-related apoptosis. Gene array analysis was used to compare the patterns of genes up- or down-regulated in $\mathrm{E}_{2}$-sensitive and -insensitive cells. For some genes, changes in mRNA expression were confirmed by protein expression analyses. Changes found in response to $E_{2}$ in multiply passaged cells, but not minimally passaged cells, included induction of growth arrest and DNA damageinducible protein 153 (GADD153), and repression of Kirsten-Ras 2B (K-Ras-2B), metastasis inhibition factor NM23 and vascular endothelial growth factor. A second
\end{abstract}

group of genes was regulated with $\mathrm{E}_{2}$ exposure in both cell types, and is unlikely to be critically involved in $\mathrm{E}_{2}$-associated apoptosis. These included up-regulation of butyrate response factor 1 (BRF1) and down-regulation of $\mathrm{c}$-jun and the breast cancer associated ring domain gene known as BARD1. By comparing control arrays from the two cell populations, cAMP-response element-binding protein (CBP), which is associated with steroid receptordependent target gene transcription and the oncoprotein, tyrosine kinase-T3 (TRK-T3), were up-regulated whereas retinoic acid receptor $\alpha(\operatorname{RAR} \alpha)$ was downregulated in multiply passaged cells. This study provides evidence for selective regulation of genes in colon cancer cells by $\mathrm{E}_{2}$, indicates which of those regulated are likely to be involved in induced apoptosis, and suggests genes likely to be responsible for facilitation.

Journal of Endocrinology (2004) 181, 327-337

\section{Introduction}

Epidemiological studies show that postmenopausal hormone replacement therapy (HRT) treatment in women is associated with a decrease in the incidence of colorectal cancer (Calle et al. 1995, Herbert-Croteau 1998, Grodstein et al. 1999). Consistent with a protective effect of female sex hormones, animal models show that male rats have higher risks of developing colon cancer compared with their female counterparts when exposed to dimethylhydrazine, an experimental carcinogen (Smirnoff et al. 1999). The effects of $17 \beta$-oestradiol $\left(E_{2}\right)$ are mediated by two specific, high-affinity receptors, oestrogen receptor $\alpha(E R \alpha)$ and oestrogen receptor $\beta$ $(\mathrm{ER} \beta)$, which modulate gene expression by interaction with oestrogen response elements or other transcription factors, such as AP1 and Sp1 (Kuiper et al. 1997, Muramatsu \& Inoue 2000). In colonic epithelial cells, ER $\beta$ predominates and transformation to the malignant phenotype is accompanied by a loss in $\operatorname{ER} \beta$ (Foley et al. 2000, Campbell-Thompson et al. 2001). Our previous study using the colon cancer cell line COLO 205 showed that $E_{2}$ induces apoptosis at physiological concentrations through ER $\beta$ by a genomic pathway (Qiu et al. 2002). This may be one of the mechanisms by which $\mathrm{E}_{2}$ can prevent colon cancer.

Several studies have examined $\mathrm{E}_{2}$-mediated apoptosis in non-colonic cells. An erythroid transcription factor, GATA-1, essential for survival and maturation, is reported to be decreased in $\mathrm{E}_{2}$-induced apoptosis in an erythroid cell line (Blobel \& Orkin 1996). In E8 CASS breast cancer cells, where $\mathrm{E}_{2}$ treatment decreases proliferation and increases DNA degradation, E9, a gene homologous to Requiem, plays a central role in $\mathrm{E}_{2}$-mediated breast cancer regression (Szelei et al. 2000). Subsequent studies on $\mathrm{E}_{2}$-sensitive breast cancer cells showed that FasL expression is increased by $\mathrm{E}_{2}$ (Song et al. 2001), a mechanism also thought to be needed for ER $\beta$-induced apoptosis in neuronal cells (Nilsen et al. 2000) while activation of p38 mitogen-activated protein kinase is coupled to ERinduced apoptosis in stably transfected ER $\alpha$-positive HeLa-ER5 cells (Zhang \& Shapiro 2000). 
$\mathrm{E}_{2}$ has, however, been linked to both promotion and prevention of cancer (Russo et al. 2002) and it is not known whether the targets activated in the prevention of cancer are the same, overlapping or distinct from those affecting promotion or other effects. cDNA array technology provides a rapid and effective method of detecting differential gene expression (Ramsay 1998). We have identified two populations of COLO 205 cells, only one of which is sensitive to $E_{2}$ in apoptosis assays. The populations differ in passage number, the later passage cells being $\mathrm{E}_{2}$ sensitive, but they do not differ markedly in growth rate or in morphology. cDNA array was used to identify the genes involved in $\mathrm{E}_{2}$-induced effects in the two populations of COLO 205. The arrays allowed us to distinguish genes involved in $\mathrm{E}_{2}$-mediated apoptosis from other $\mathrm{E}_{2}$-regulated genes. For several genes, Western immunoblotting was used to confirm the cDNA array results. Furthermore, by comparing arrays from unstimulated cells, we have identified genes likely to be involved in the transformation to an $\mathrm{E}_{2}$-sensitive phenotype.

We have provided the first step in identifying the gene pathways by which $\mathrm{E}_{2}$ could prevent colon cancer, showing that induction of growth arrest and DNA damageinducible protein 153 (GADD153) and repression of Kirsten-RAS-2B (K-Ras-2B) oncoprotein and metastasis inhibition factor NM23 (NM23-H1) contribute to $\mathrm{E}_{2^{-}}$ induced apoptosis in COLO 205 cells. Additional pathways demonstrate that $\mathrm{E}_{2}$ may inhibit pathogenic angiogenesis by inhibition of vascular endothelial growth factor (VEGF) production.

\section{Materials and Methods}

\section{Materials}

COLO 205 cells, derived from the ascites fluid of a 70-year-old Caucasian male with colorectal cancer, were purchased from the European Animal Cell Culture Collection (EACC, Porton Down, Wilts, UK). In our study, COLO 205 cells between passages 5 and 20 are identified as NCOLO 205 and those from passage $>40$ are designated OCOLO 205. HT-29 cells (EACC), established from the primary tumour of a 44-year-old Caucasian, were used as comparators. For experiments used in the arrays, cyclodextrin-encapsulated $\mathrm{E}_{2}$ (watersoluble $\mathrm{E}_{2}$ from Sigma Chemical Corporation, Poole, Dorset, UK) was dissolved in Milli-Q distilled water (Millipore Ltd, Stonehouse, Glos, UK), at a stock concentration of $10^{-2} \mathrm{M}$ and 2-hydroxypropyl- $\beta$-cyclodextrin (Sigma) was used as control for this agent. TRIzol was purchased from Invitrogen Ltd (Paisley, Strathclyde, UK). Atlas human cancer $1 \cdot 2 \mathrm{cDNA}$ arrays were obtained from BD Biosciences Clontech UK (Oxford, Oxon, UK).
Assays of DNA fragmentation following treatment with $E_{2}$

OCOLO 205 and NCOLO 205 cells were serum-starved for $24 \mathrm{~h}$. Following a medium change, $\mathrm{E}_{2}\left(10^{-12} \mathrm{M}\right.$ and $10^{-11} \mathrm{M}$ ) was added to some wells and incubation was continued for a further $48 \mathrm{~h}$. Vehicle (DMSO) was added to the control wells. Assays of DNA fragmentation on the floating cells were performed as described previously (Qiu et al. 2002).

\section{Cell culture and treatment}

Cell lines were maintained in phenol-red free RPMI 1640 medium (Sigma) augmented with 10\% foetal bovine calf serum (FCS; First Link Ltd, Birmingham, UK), 100 U/ml penicillin $\mathrm{G}$ and $100 \mu \mathrm{g} / \mathrm{ml}$ streptomycin sulphate (Sigma) in a humid atmosphere at $37^{\circ} \mathrm{C}$, with $5 \% \mathrm{CO}_{2}$. Cells were passaged twice a week and plated at a density of $5 \times 10^{4}$ cells $/ \mathrm{cm}^{2}$ and cultured for 3 days in $10 \%$ charcoalstripped FCS (CSFCS), followed by treatment with $\mathrm{E}_{2}$ for the indicated periods of time in serum-free medium in the presence of antibiotics. CSFCS was prepared by mixing $50 \mathrm{ml}$ FCS with $5 \mathrm{~g}$ activated charcoal (Sigma) overnight at $4{ }^{\circ} \mathrm{C}$. Following centrifugation to remove the charcoal, another $5 \mathrm{~g}$ charcoal was added to the supernatant, incubated for $30 \mathrm{~min}$ at $37^{\circ} \mathrm{C}$ and removed by centrifugation. This was repeated once.

\section{Preparation of total RNA}

Floating and adherent cells were pooled. Total RNA was extracted from cells using TRIzol reagent according to the manufacturer's recommendations and quantified by spectrometry $(260 \mathrm{~nm})$. The removal of possible DNA contaminants from extracted RNA was performed with RQ1 RNase-free DNase I (Invitrogen) digestion followed by phenol:chloroform:isoamyl alcohol extraction of RNA. The quality of RNA was assured by gel electrophoresis of $4 \mu \mathrm{g}$ extracted RNA on $1 \%$ agarose/ethidium bromide gel with clear $28 \mathrm{~S}$ and $18 \mathrm{~S}$ bands, and the ratio of $28 \mathrm{~S}$ to $18 \mathrm{~S}$ ribosomal RNA was about 2.

\section{cDNA expression array analysis}

To identify genes regulated by $E_{2}$, a human cDNA array that contained 1176 genes was screened using radiolabelled cDNA generated from total RNA extracted from NCOLO 205 ( $\mathrm{E}_{2}$-apoptosis resistant) and OCOLO 205 ( $\mathrm{E}_{2}$-apoptosis sensitive) cells treated with or without $\mathrm{E}_{2}$ $(1 \mathrm{nmol} / \mathrm{l})$ for $8 \mathrm{~h}$ and for $24 \mathrm{~h}$. Detection of mRNA expression was performed according to the manufacturer's instructions. Briefly, high sensitivity probes were synthesised by in vitro transcription with $\alpha-\left[{ }^{33} \mathrm{P}\right] \mathrm{ATP}$ and the gene-specific CDS primer mix provided, and purified by column chromatography (BD Biosciences Clontech UK). Hybridisation was performed overnight with continuous 
agitation at $68^{\circ} \mathrm{C}$, followed by stringent washing to remove non-specific binding. Signals were detected by exposure of the hybridised atlas arrays to a phosphorimager screen for 3-6 days at room temperature, scanned using Molecular Imager FX (BioRad, Hercules, CA, USA) and data were analysed by Atlasimage 1.5 software (BD Biosciences Clontech UK). To ensure accurate comparison between different membranes, signals were normalised to the sum of all of the genes, as suggested by the manufacturer, since most of the genes detected will not be regulated. Gene regulation was taken into account only when genes were up-regulated by more than 2 -fold or down-regulated by more than $50 \%$.

\section{Western immunoblotting}

Floating and adherent COLO 205 cells were pooled and washed with HBSS twice, and solubilised in lysis buffer (2\% SDS, $62 \cdot 5 \mathrm{mmol} / 1$ Tris- $\mathrm{HCl}, \mathrm{pH} 6 \cdot 8)$. Protein concentration was assayed using the BioRad $D c$ protein assay kit (BioRad) with bovine serum albumin (BSA) as standard. Protein $(100 \mu \mathrm{g})$ was separated by electrophoresis on $15 \%$ SDS-PAGE with a $7 \cdot 5 \%$ stacking gel under reducing conditions. The separated proteins were transferred to a polyvinylidene difluoride membrane (Amersham Pharmacia Biotech Inc., Little Chalfont, Bucks, UK) for $3 \mathrm{~h}$ at $450 \mathrm{~mA}$. Non-specific binding was blocked by incubating the membrane in 10\% low-fat milk in Tris-buffered saline-Tween 20 (TBS-T; $10 \mathrm{mmol} / 1$ Tris- $\mathrm{HCl}, \mathrm{pH} 7 \cdot 5,100 \mathrm{mmol} / 1 \mathrm{NaCl}$ and $0 \cdot 1 \%$ Tween 20) for $1 \mathrm{~h}$ at room temperature. The blot was incubated with 1:1000 dilution of anti-GADD153 (Santa Cruz Biotechnology Inc., Santa Cruz, CA, USA) or anti-KRas-2B antibody (Santa Cruz) or 1:500 dilution of antibody against NM23-H1 (Santa Cruz) in TBS-T with $0 \cdot 25 \%$ BSA overnight at $4{ }^{\circ} \mathrm{C}$. After exposure to primary antibody, the blot was washed in TBS-T and incubated with horseradish peroxidase (HRP)-conjugated anti-rabbit immunoglobulin (1:50000 dilution in TBS- $\mathrm{T}$ with $0 \cdot 25 \%$ BSA; Santa Cruz) or HRP-conjugated anti-mouse immunoglobulin (1:20 000) for $1 \mathrm{~h}$ at room temperature and washed again. Chemiluminescent substrate (KPL; Insight Biotechnology Ltd, Wembley, London, UK), and Kodak MXB film (GRI; Rayne, Essex, UK) were used for detection of immunoreactive species. For some blots, further confirmation of equal loading was shown by stripping the membranes in $2 \%$ SDS, $1 \%$ 2-mercaptoethanol and $62.5 \mathrm{mmol} / 1$ Tris- $\mathrm{HCl}, \mathrm{pH} 6.8$ at $60{ }^{\circ} \mathrm{C}$ for $30 \mathrm{~min}$, and, following extensive washing, reprobing with antisera to cytokeratin 8 (the binding site).

\section{ELISA}

Cell-conditioned media were collected from OCOLO 205 and NCOLO 205 cells treated with varying doses of $\mathrm{E}_{2}$ in triplicate wells for $48 \mathrm{~h}$. At collection, FCS $(1 \%$

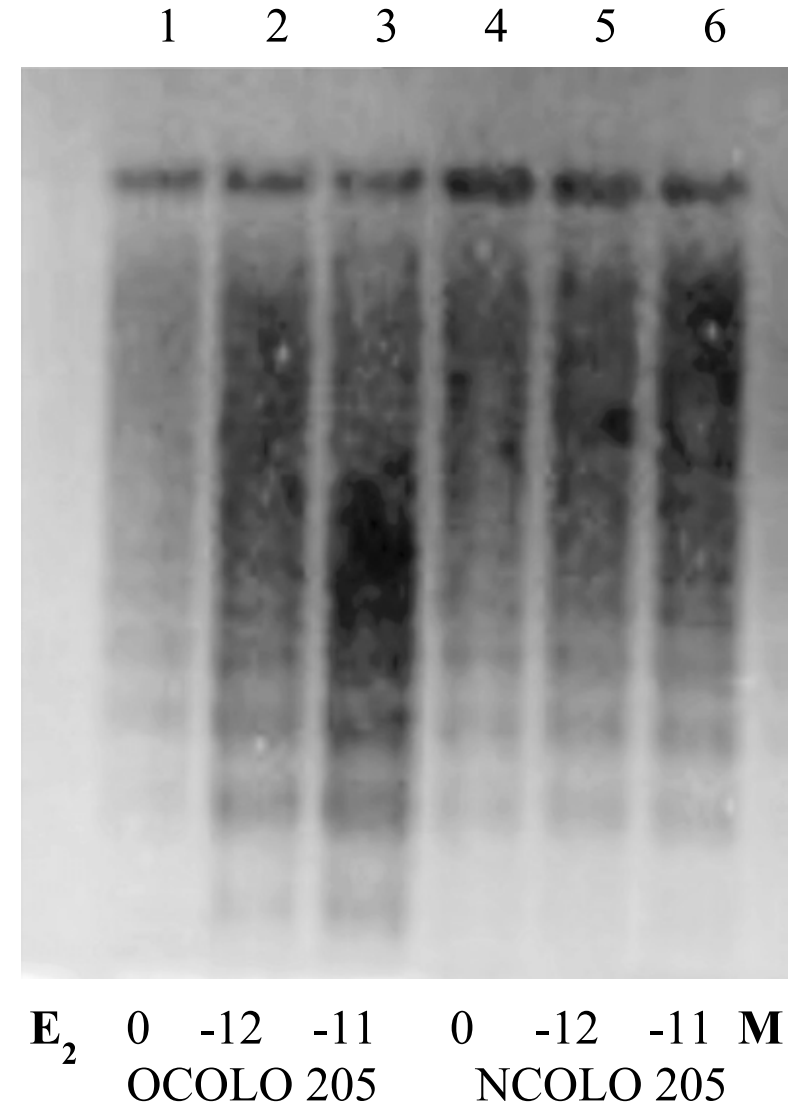

Figure 1 Effect of $E_{2}$ on DNA fragmentation in OCOLO 205 and NCOLO 205 cells. Lanes 1-3 are from OCOLO 205 cells and lanes 4-6 are from NCOLO 205 cells. Lanes 2 and 5 were from cells challenged with $10^{-12} \mathrm{ME}_{2}$ and lanes 3 and 6 from cells challenged with $10^{-11} \mathrm{M} \mathrm{E}_{2}$.

final concentration) was added to prevent loss of VEGF and samples were frozen at $-20{ }^{\circ} \mathrm{C}$ until use. ELISA was performed as suggested by the manufacturer ( $R \& D$ Systems Europe Ltd, Abingdon, Oxon, UK). Secreted VEGF was corrected for protein content of the cell layer.

\section{Results}

Effect of $E_{2}$ on DNA fragmentation in OCOLO 205 and NCOLO 205 cells

The effects of $\mathrm{E}_{2}$ on DNA fragmentation in OCOLO 205 (>40 passages) and NCOLO 205 cells (5-20 passages), prepared as described in the Materials and Methods are shown in Fig. 1. OCOLO 205 cells showed increased DNA fragmentation with $\mathrm{E}_{2}$ treatment whereas NCOLO 205 cells were $\mathrm{E}_{2}$ insensitive.

Effects of $E_{2}$ on gene expression in OCOLO 205 and NCOLO 205 cells

Out of 1176, 35-107 (3-9\%) genes were detected with ${ }^{33} \mathrm{P}$-labelled probes on the cDNAs. Non-specific 
hybridisation was shown to be minimal since no plasmid or bacteriophage DNAs (M13 mp18(+) strand DNA, $\lambda$ DNA and pUC18 DNA) or genomic DNA included in the array were positive.

Genes regulated by $\mathrm{E}_{2}$ treatment $(1 \mathrm{nmol} / \mathrm{l})$ in OCOLO 205 but not in NCOLO 205 cells were considered likely to be involved in $\mathrm{E}_{2}$-induced apoptosis and are listed in Table 1. Using this selection criterion, 28 of $1176(2 \cdot 4 \%)$ genes were identified. Of these, seven genes were up-regulated, 18 genes down-regulated and three genes regulated bi-directionally when signals from two time-points ( 8 and $24 \mathrm{~h}$ ) were analysed. Genes previously shown to be regulated by $\mathrm{E}_{2}$ are indicated with an asterisk.

The gene encoding growth arrest and DNA damageinducible protein (GADD153), a stress- and apoptosisassociated gene, showing induction or overexpression associated with endoplasmic reticulum stress (Ubeda \& Habener 2000, Maytin et al.) or apoptosis induced by u.v. light (Luethy et al. 1990, Gujuluva et al. 1994, Kawahara et al. 2001) was increased 5·3-fold. Other genes that were up-regulated included those encoding TRAP1 (15-fold), sentrin (8-fold) and SHMT (3.8-fold) .

In contrast, the gene encoding $\mathrm{K}-\mathrm{R}$ as $-2 \mathrm{~B}$, a $\mathrm{G}$ protein involved in cell proliferation, was decreased by $80 \%$ with $\mathrm{E}_{2}$ treatment in OCOLO 205 cells, NM23-H1 was decreased by $26 \%$ at $8 \mathrm{~h}$ and by $78 \%$ at $24 \mathrm{~h}$ and VEGF, an angiogenesis factor, was also decreased. Other genes repressed by $\mathrm{E}_{2}$ include those encoding ERBB-3 receptor protein-tyrosine kinase precursor (90\% inhibition), myc (60\%), GRP 78, bax (66\%) as well as the P68 TRK-T3 oncoprotein.

\section{Target verification by Western immunoblotting analysis and ELISA}

Confirmation that the mRNA expression changes were translated to changes in protein expression was obtained by Western immunoblotting using specific antisera or ELISA measurement. GADD153, K-Ras-2B, NM23-H1 and VEGF were examined. These genes were chosen somewhat arbitrarily because the primary reason to do this was to check whether the changes in mRNA expression seen in the array were reflected in similar changes in protein expression, but we also selected these genes because we considered them of interest as described in the Discussion. GADD153 protein was dose-dependently increased with $\mathrm{E}_{2}$ treatment in OCOLO 205 cells (Fig. 2a), while expression of oncoprotein K-Ras-2B (Fig. 2b) and NM23-H1 (Fig. 2c) were down-regulated. In NCOLO 205 cells, these genes were not regulated by $\mathrm{E}_{2}$ treatment (Fig. $2 \mathrm{~d}$ and e). Similarly, in another colon cancer cell line, HT-29, which did not apoptose in response to $\mathrm{E}_{2}$, neither GADD153 (Fig. 2f) nor K-Ras-2B (Fig. 2g) was regulated by $\mathrm{E}_{2}$.

Inhibition of VEGF secretion by $E_{2}$

Figure 3 shows the effect of $E_{2}$ on VEGF secretion from OCOLO 205 cells. $\mathrm{E}_{2}$ treatment produced dose-dependent reduction in VEGF secretion in OCOLO 205 cells that was significant at $1 \mathrm{nM} \mathrm{E}_{2}$. No significant changes in VEGF expression were found in NCOLO 205 cells. Comparable amounts of VEGF were secreted by NCOLO 205 and OCOLO 205 control cells.

\section{Identification of $E_{2}$-responsive genes common to OCOLO 205 and NCOLO 205 cells}

Significant and equivalent up-regulation of four genes and down-regulation of nine genes were detected in both NCOLO and OCOLO 205 cells (Table 2). These include BRF1 and ELF1 which were increased, and the breast cancer associated ring domain gene known as BARD1 and c-jun which were decreased.

\section{Differences between untreated OCOLO 205 and NCOLO 205 cells detected with cDNA array}

By analysing the differences in cDNA array between OCOLO 205 and NCOLO 205 cells not treated with $\mathrm{E}_{2}$, we were able to identify genes likely to be involved in the increased sensitivity of OCOLO 205 cells. These data are shown in Table 3. OCOLO 205 cells were found to express 5-fold more cAMP-response element (CREB)binding protein (CBP) than NCOLO 205 cells when incubated in serum-free medium for $24 \mathrm{~h}$. Expression levels of the oncoprotein TRK-T3 were 10-fold greater whereas $\operatorname{RAR} \alpha$ mRNA was decreased in multiply passaged cells.

\section{Discussion}

By comparing findings in OCOLO 205 and NCOLO 205 colonic cancer cells which respectively respond and do not respond by apoptosis to physiologic concentrations of $\mathrm{E}_{2}$, we have been able to show that there is evidence of selective up- and down-regulation of genes either predisposing to or protecting from apoptosis in the cells which are responsive. Some of these are genes previously identified as $\mathrm{E}_{2}$ responsive in non-colonic cancer cells, but others have not been so identified. We have sought for and found that there are parallel and appropriate responses in OCOLO 205 but not in NCOLO 205 cells in protein expression for some of these genes. This confirmatory evidence of appropriate changes in protein expression establishes the reliability of the cDNA array data although it must be appreciated that the arrays were not performed to the same exacting rigour as that recently described by Lobenhofer et al. (2002). Our study aimed to establish the principle of this approach and to confirm the array data at the protein expression level. Unresponsiveness of HT-29 colon cancer cells to $\mathrm{E}_{2}$ in the expression of target genes further confirmed that these genes are likely involved in apoptosis induction by $\mathrm{E}_{2}$. 
Table 1 Apoptosis-associated genes: genes regulated by $E_{2}$ in OCOLO 205 but not NCOLO 205 cells. Gene regulation was considered significant when the increase is $>2$-fold or the decrease is $>50 \%$

\section{Genes up-regulated}

Tumour necrosis factor type 1 receptor-associated protein (TRAP1)

Growth arrest and DNA damage-inducible protein 153 (GADD153)

Ubiquitin-like protein SMT3C (sentrin)

\section{KIAA0078}

40S ribosomal protein S16

Cytosolic serine hydroxylmethyltransferase (SHMT)

$\mathrm{BIGH} 3 /$ keratoepithelin protein

\section{Genes down-regulated}

${ }^{*} \mathrm{myc}$

*Nucleoside diphosphate kinase A (NDKA); metastasis inhibition factor NM23 (NM23-H1)

*ERBB-3 receptor protein-tyrosine kinase precursor; epidermal growth factor receptor

ADP/ATP carrier protein; fibroblast adenine nucleotide translocator 2 (ANT2)

Ras-related C3 botulinum toxin substrate 2; p21-rac2; small G protein Ras-related C3 botulinum toxin substrate 1; p21-rac1; ras-like protein TC25 RhoGDP dissociation inhibitor 1 (Rho-GDI1); Rho-GDI $\alpha$ (RDIA1);

$$
\text { ARHGDIA }
$$

*78 kDa glucose-regulated protein precursor (GRP 78)

*Bone morphogenetic protein 4 (BMP4) + bone morphogenetic protein 2B (BMP2B)

Macrophage inhibitory cytokine 1 (MIC1)

*Erythroid potentiating activity (EPA); fibroblast collagenase inhibitor TIMP1

\section{$\stackrel{0}{\searrow}$ TRAMP protein}

${ }^{*} \mathrm{v}$-ki-RAS2B proto-oncogene (KRAS2)

RBP2 retinoblastoma binding protein

${ }^{*}$ Apoptosis regulator bax

trk-T3; P68 TRK-T3 oncoprotein

CENP-F kinetochore protein

*VEGF precursor; vascular permeability factor (VPF)

\section{Genes regulated bi-directionally}

Early growth response protein 1 (hEGR 1 )

Cartilage-specific proteoglycan core protein (CSPCP)

*Bone morphogenetic protein 2A (BMP2A)

${ }^{*}$ Genes previously shown in the literature to be regulated by $E_{2}$.

Fold induction

Accession

number

U12595

S40706

U83117

D38551

M60854

L11931

M77349

V00568

$\mathrm{X} 17620$

M29366

J02683 P05141

M64595

M29870

$\times 69550$

M19645

D30751

AF019770

X03124 P01033

X63679

M54968

S66431

L22474

X85960

U19769

M32977 M27281

X5254

M55172 P16112

M22489

$8 \mathrm{~h} 24 \mathrm{~h}$

$15 \cdot 81$

$5 \cdot 32$

8.55

$14 \cdot 9$

$2 \cdot 04$

$3 \cdot 75$

$2 \cdot 18$

\% Reduction

$67 \quad 57$

\section{Classification}

Death receptor-associated proteins and adaptors

Stress response proteins, apoptosis-associated proteins Enzymes involved in protein turnover, apoptosis-associated proteins

DNA damage repair proteins and ligases

Ribosomal proteins

Amino acid, nucleotide and lipid metabolism

Microfilament proteins

Transcription activators and repressors

Apoptosis-associated proteins, transcription activators

Growth factor and chemokine receptors

Symporters and antiporters

\section{Groteins}

G proteins

GTP/GDP exchangers and GTPase activity modulators

Immune system proteins, heat shock protein

Growth factors, cytokines and chemokines

Growth factors, cytokines and chemokines Protease inhibitors

Trafficking proteins

Oncogenes and tumour suppressors, G proteins

Transcription factors, cell cycle proteins

$\mathrm{BCl}$ family proteins

Growth factor and chemokine receptors

DNA-binding and chromatin proteins

Growth factors, cytokines and chemokines

Transcription activators and repressors

Extracellular matrix proteins

Growth factors, cytokines and chemokines 


\section{OCOLO 205}

a) GADD153

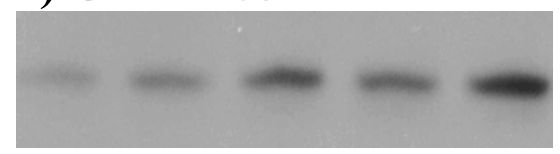

Cytokeratin 8

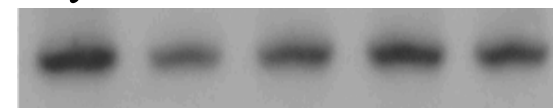

Con $10^{-11} 10^{-10} 10^{-9} 10^{-8}$

b) K-Ras-2B

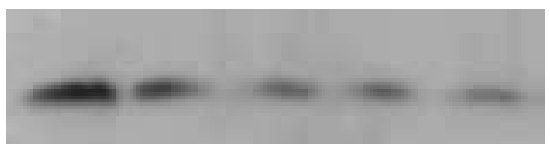

Cytokeratin 8

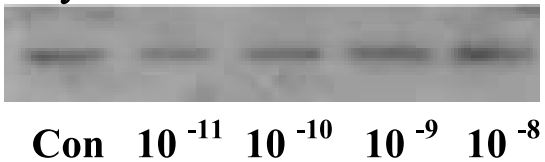

c) $\mathbf{N M - 2 3}$

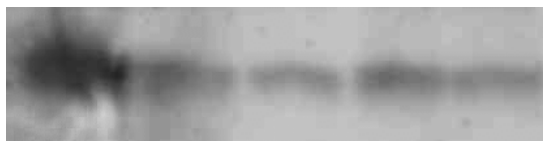

Cytokeratin 8

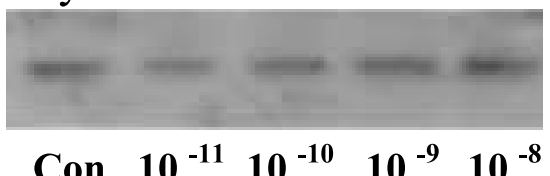

NCOLO 205

d) GADD153

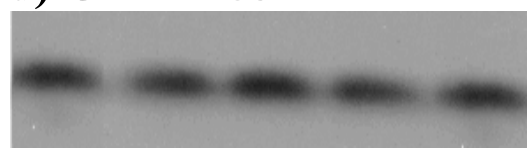

Cytokeratin 8

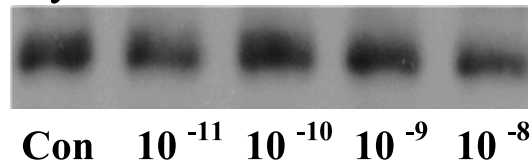

e) K-Ras-2B

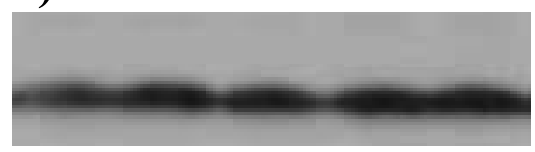

Cytokeratin 8

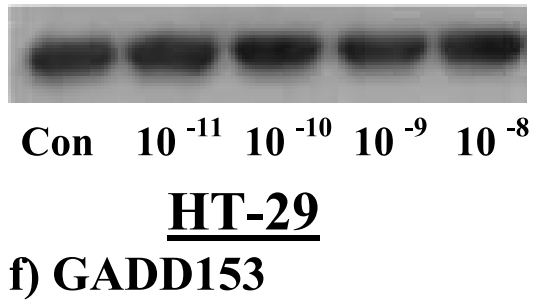

Con $10^{-11} 10^{-10} 10^{-9} 10^{-8}$

g) K-Ras-2B

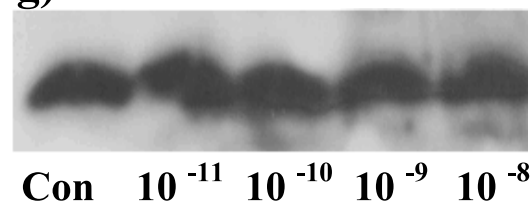

Figure 2 Western blots showing expression of (a) GADD153, (b) K-Ras-2B and (c) NM23-H1 (NM-23) expression in OCOLO 205 cells following $E_{2}$ treatment. Expression of (d) GADD153 and (e) K-Ras-2B in NCOLO 205 cells and (f) GADD153 and (g) K-Ras-2B in HT-29 cells following $\mathrm{E}_{2}$ treatment are shown. (a-e) Blots were stripped and reprobed with cytokeratin 8 as further confirmation of equal loading and these blots are shown in the lower blots of each pair. Cells were cultured in 10\% CSFCS for 3 days before treatment with various concentrations of $\mathrm{E}_{2}$ for $24 \mathrm{~h}$ in serum-free media. Protein was extracted, equal amounts were loaded onto SDS-PAGE and Western immunoblotting was performed. Representative images are shown. Con, control.

$\mathrm{E}_{2}$ treatment in OCOLO 205 cells induced GADD153, a leucine zipper transcription factor able to heterodimerise with members of the CEBP family of transcription factors (Ron \& Habener 1992). It was originally identified based on its induction following treatment of cells with growtharresting and DNA-damaging agents. GADD153 has been correlated with the onset of apoptosis through downregulation of Bcl-2 (McCullough et al. 2001), p38 and other mechanisms (Russo et al. 2002). Studies in GADD153 knockout mice suggest a role in apoptosis during the endoplasmic reticulum stress response in kidney cells (Bruhat et al. 1997). In a study using gene array and 


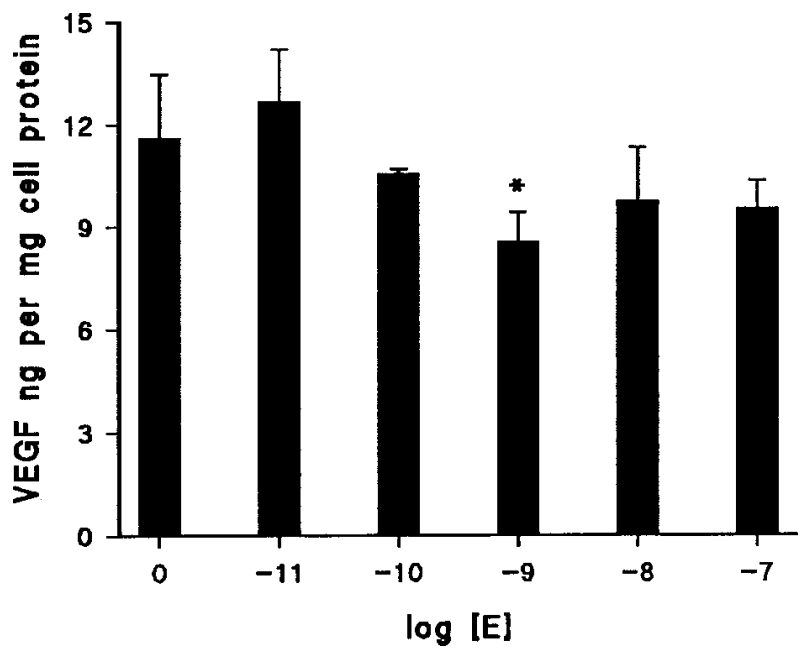

Figure 3 Effect of $E_{2}$ treatment on secretion of VEGF measured by ELISA. Conditioned media were collected from triplicate wells of OCOLO 205 cells treated with $E_{2}$ for $48 \mathrm{~h}$. The amount of VEGF secreted was corrected for $m g$ cell protein and plotted against $E_{2}$ concentration. Values are means \pm S.D. $(n=3) .{ }^{*} P<0 \cdot 05$ (ANOVA and Dunnett's post test).

HT-29 colon cancer cells, GADD153 expression was increased following activation of peroxisome proliferatoractivated receptor $\gamma$ which induced apoptosis in these cells (Shimada et al. 2002).

TRAP1, which binds to the intracellular domain of the tumour necrosis factor receptor, was also significantly increased. TRAP1 is postulated to be a direct myc target, as part of a pathway that leads to increased apoptosis in myc-overexpressed cells (Coller et al. 2000). Up-regulation of cytosolic serine hydroxymethyltransferase (SHMT) by $\mathrm{E}_{2}$ was unexpected. SHMT is a key enzyme involved in folate metabolism (Stover et al. 1997). Much epidemiological and experimental evidence is in accord with such protection from colon cancer by folate (Choi \& Manon 2000) and our result suggests that there may be mechanistic features in common between $\mathrm{E}_{2}$ and folate protection.

$\mathrm{E}_{2}$ treatment also led to down-regulation of $78 \mathrm{kDa}$ glucose-regulated protein (GRP 78) in OCOLO 205 cells. GRP 78 is a chaperone that guides proteins through the folding process, and the up-regulation in response to endoplasmic reticulum stress increases the cell's capacity to cope with the accumulation of immature, misfolded proteins in the endoplasmic reticulum. If GRP 78 induction is prevented, cell survival diminishes greatly following treatment with agents that stress the endoplasmic reticulum (Jamora et al. 1996).

Activating Ras mutation occurs in $50 \%$ of colon cancer and $90 \%$ of these are K-Ras mutations associated with the early stage of colon cancer development (Gryfe et al. 1997). Two isoforms generated by alternative splicing of $\mathrm{K}-\mathrm{R}$ as exist, i.e. K-Ras-2A, which is relatively rare, and
K-Ras-2B. Sequencing of the COLO 205 K-Ras-2B gene (data not shown) showed that it is mutated in codon 6 leading to a leucine to proline change but whether this is an activating mutation is not known. Down-regulation of K-Ras-2B by treatment with $\mathrm{E}_{2}$ was confirmed by both cDNA array analysis and Western immunoblotting consistent with an $\mathrm{E}_{2}$-mediated reduction in the proliferative and anti-apoptotic properties of $\mathrm{K}-\mathrm{R}$ as-2B.

Evidence is accumulating that $\operatorname{ER} \alpha$ and $\operatorname{ER} \beta$ function differently and our findings support this. We found down-regulation of both NM23-H1 and VEGF in ER $\beta$ expressing cells by $\mathrm{E}_{2}$ in OCOLO 205 cells whereas, in three ER $\alpha$-dominant breast cancer cell lines, an increase in NM23-H1 expression was seen (Lin et al. 2002) and, in MCF-7 cells which express ER $\alpha$, VEGF was increased by $\mathrm{E}_{2}$ treatment (Bogin \& Degani 2002). NM23-H1 was first identified as a metastatic inhibitor in a murine melanoma cell line (Steeg et al. 1988). Expression of the human NM23 homologue is also lower in human breast cancers of high metastatic potential than in breast cancers of low metastatic potential (Bevilacqua et al. 1989). However, Haut et al. (1991) reported that, in the colon, no difference in the expression of NM23-H1 was found among colon tumours with high and low metastatic potential (Haut et al. 1991). Furthermore, in addition to its correlation with metastasis, NM23-H1 expression is also directly related to cell proliferative activity (Keim et al. 1992). Further clarification of its role in cell cycle control is clearly needed.

Neovascularisation is a critical requirement for tumour growth and metastasis. A connection between $\mathrm{E}_{2}$ exposure and inhibition of angiogenesis is suggested by inhibition of VEGF mRNA and protein secretion. Higher concentrations of $\mathrm{E}_{2}(1 \mathrm{nmol} / \mathrm{l})$ were required to decrease VEGF secretion than to induce apoptosis $(10 \mathrm{pmol} / \mathrm{l})$ in the cells but the effects of VEGF are paracrine, to act on the endothelial cells, and not involved in the apoptosis effected by $\mathrm{E}_{2}$. Several studies have suggested that VEGF is the angiogenic factor most closely associated with induction and maintenance of the neovasculature in human colon cancer (Takahashi et al. 1995, 1997, Ellis et al. 1996, Warren et al. 1996). In primary tumours, the expression of VEGF mRNA is increased in tumours relative to histologically normal bowel mucosa (Berse et al. 1992, Brown et al. 1993) and further analyses have implicated VEGF expression in tumour progression and metastasis (Warren et al. 1995).

If the genes which we have identified as up- or down-regulated by $\mathrm{E}_{2}$ in apoptosis-sensitive cells are causally associated, then overlap with findings in other cell types is to be expected. Ten (36\%) of the identified genes have been previously reported to be targets of $\mathrm{E}_{2}$. The other genes, not previously linked with $\mathrm{E}_{2}$-associated apoptosis outside the colon therefore deserve further study. Among proteins known to be involved in apoptosis but not previously shown to be regulated by $\mathrm{E}_{2}$ are TRAP1, 
Table $2 \mathrm{E}_{2}$-responsive but not apoptosis-related genes: genes regulated by $\mathrm{E}_{2}$ in both OCOLO 205 and NCOLO 205 cells. Gene regulation was considered significant when the increase is $>2$-fold or the decrease is $>50 \%$

\section{Genes up-regulated}

Endonuclease III homolog 1 (HNTH1) (OCTS3)

Putative regulatory protein TGF $\beta$-stimulated clone 22 homologue (TSC22)

TIS11B protein; EGF response factor 1 (ERF1); butyrate response factor 1 (BRF1)

ets-related transcription factor E74-like factor 1 (ELF1)

\section{Genes down-regulated}

${ }^{*} \mathrm{C}$-jun proto-oncogene; *transcription factor AP-1

J04111

56

U24166

61

U49089

Synapse-associated protein 102 (SAP102);

neuroendocrine-DLG (NE-DLG; DLG3;

human homologue of Drosophila discs large (DLG)

retinoic acid activated CDNA1 (RATS1)

BRCA1-associated ring domain protein

$\mathrm{V}(\mathrm{D})$ J recombination activating protein 1 (RAG1)

rac- $\alpha$ serine/threonine kinase (rac-PK $\alpha$ );

*protein kinase B (PKB); c-akt; akt1

fibroblast growth factor homologous factor (FHF-1)

Ku 70 kDa subunit; ATP-dependent DNA helicase II 70 kDa subunit; lupus ku autoantigen protein P70; thyroid-lupus auto-antigen (TLAA); CTC box binding factor $75 \mathrm{kDa}$ subunit (CTC75)

U37688

99

99

\begin{tabular}{|c|c|c|}
\hline \multirow{2}{*}{$\begin{array}{l}\text { Accession } \\
\text { number }\end{array}$} & \multicolumn{2}{|c|}{ Fold induction by $24 \mathrm{~h}$} \\
\hline & NCOLO 205 & OCOLO 205 \\
\hline U79718 & $3 \cdot 71$ & $14 \cdot 02$ \\
\hline U35048 & $10 \cdot 92$ & $9 \cdot 88$ \\
\hline X79067 & 34 & $16 \cdot 52$ \\
\hline \multirow[t]{2}{*}{ M82882 } & \# & $8 \cdot 96$ \\
\hline & \multicolumn{2}{|c|}{$\%$ reduction by $24 \mathrm{~h}$} \\
\hline
\end{tabular}

\section{Classification}

DNA damage repair proteins and ligases

Transcription activators and repressors

Transcription activators and repressors

Transcription activators and repressors

Oncogenes and tumour suppressors

Transcription activators and repressors

Intracellular transducers, effectors and modulators

Oncogenes and tumour suppressors

Intracellular transducers, effectors and modulators

Oncogenes and tumour suppressors

Other apoptosis-associated proteins

Cell cycle-related proteins

Oncogenes and tumour suppressors

Transcription activators and repressors

Transcription activators and repressors

Recombination proteins

Death kinases, intracellular kinase network members,

Oncogenes and tumour suppressors

Transcription proteins

DNA damage repair proteins and ligases

DNA polymerases, replication factors and topoisomerases

Stress response proteins

*Genes previously reported to be regulated by $E_{2}$.

\#There was no expression in control cells; TGF, transforming growth factor; EGF, epidermal growth factor. 
Table 3 Genes showing a greater than 5-fold difference between OCOLO 205 and NCOLO 205 cells (O:N) by cDNA array. Analyses were performed on mRNAs isolated from cells incubated in serum-free conditions for 8 and $24 \mathrm{~h}$

\section{Name of gene}

(1) Placental calcium-binding protein; calvasculin; S100 calcium-binding protein A4; MTS1 protein

(2) Retinoic acid receptor $\alpha 1$

(3) CREB-binding protein $\mathrm{C} 12 \mathrm{~m}$

(4) trk-T3; P68 TRK-T3 oncoprotein

(5) Tenascin precursor; hexabrachion; cytotactin; neuronectin; miotendinous antigen; glioma-associated extracellular matrix antigen

(6) Elongation factor 2

(7) human transforming growth factor $\beta$ induced gene product (BIGH3)

sentrin, 40S ribosomal protein S16, and RAD21 which were all increased. Genes down-regulated, not previously shown to be $\mathrm{E}_{2}$ sensitive, include retinoblastoma binding protein 2 which has been shown to potentiate nuclear hormone receptor-mediated transcription (Chan \& Hong 2001) and the tissue inhibitor of metalloprotease 1 (TIMP1).

We have identified several genes that were regulated by $\mathrm{E}_{2}$ in both NCOLO 205 and OCOLO 205 cells. This suggests that if these genes are involved in apoptosis, then either they are not critical, or they lie on alternative pathways not facilitated completely by $\mathrm{E}_{2}$. BRF1 was markedly increased in both cell strains. BRF1 is an immediate early gene which is induced rapidly and usually transiently in response to growth factor or hormone stimulation. In HT-29 cells this gene was down-regulated by butyrate which induces differentiation in these cells (Maclean et al. 1998). The transcription factor ELF1 was also increased in both cell types. C-jun which acts with c-fos to form the transcription factor AP1 was down-regulated as was breast cancer type I susceptibility protein 1 (BRCA1)associated ring domain protein (BARD1). Half of familial breast cancer cases are found to have mutations, usually resulting in truncations, in the breast cancer susceptibility gene, BRCA1. Significant although lesser excesses were also observed for colon cancer (Ford et al. 1994). BARD1 is one of several partners that can interact with BRCA1. In mammary epithelial cells, reductions in BARD1 with antisense RNAs induced a premalignant phenotype, suggesting that it could function as a tumour suppressor. In the colon cancer cells, we found that physiological concentrations of $\mathrm{E}_{2}$ induced marked reductions in BARD1 at $24 \mathrm{~h}$. Whether the cells express BRCA1, what the function of either protein is, and whether the cells express mutated forms of either protein awaits clarification. That BARD1 may have importance in colon carcinogenesis is indicated in a study which showed that autoantibodies to cleaved BARD1 have antitumoral activity against colon cancers (Gautier et al. 2000).
GeneBank no.

M80563

X06538; X06614+M73779

$\cup 47741$

X85960

X78565; M55618

X51466

M77349
$\mathrm{O}: \mathrm{N}$ at $8 \mathrm{~h}$

$-0 \cdot 31$

$5 \cdot 11$
$10 \cdot 22$

$-0 \cdot 81$

$-0 \cdot 79$

$-0 \cdot 81$

$-0 \cdot 84$

$5 \cdot 11$

$0 \cdot 22$
$\mathrm{O}: \mathrm{N}$ at $24 \mathrm{~h}$

$-0.91$

$-0 \cdot 88$

Possible explanations for the difference in responsiveness to $\mathrm{E}_{2}$ between OCOLO 205 and NCOLO 205 were also provided by the gene arrays. OCOLO 205 cells were found to express 5-fold more CBP than NCOLO 205 cells when incubated in serum-free and $E_{2}$-free medium for $24 \mathrm{~h}$. CBP has been discovered to bind specifically to the protein kinase A-phosphorylated form of the CREB and to enhance steroid receptor-dependent target gene transcription (Shibata et al. 1997). Greater expression of CBP in OCOLO 205 cells, which apoptose upon $\mathrm{E}_{2}$ treatment, indicates that this gene may importantly affect responsiveness to $\mathrm{E}_{2}$. The decreased expression of the mRNA for RAR $\alpha$ in the OCOLO 205 cells may also be significant in this regard. RAR $\alpha$ is an important mediator of apoptosis in many cancer cells. The relationship between the increased expression of TRK-T3 oncogene, which is a constitutively activated version of the nerve growth factor receptor, and $\operatorname{ER} \beta$ sensitivity is hard to explain, although TRK-T3 activates many signalling pathways, not all of which co-operate to increase cell transformation (Roccato et al. 2002).

We conclude that use of apparently similar cell lines which respond differently to a specific stimulus is a valuable way of obtaining insight into underlying mechanisms. Our data based on such studies suggest that there are specific apoptotic pathways activated by $\mathrm{E}_{2}$ in colon cancer cells.

\section{Acknowledgements}

We wish to express our appreciation to Dr Q T Luong, Department of Medicine, University of Birmingham, UK for technical support for cDNA array analysis and to Dr C M Bunce for helpful discussions.

\section{Funding}

This work is supported by the Department for Education and Skills, UK which provided an Overseas Research Students Award to Y Q.

Journal of Endocrinology (2004) 181, 327-337 


\section{References}

Berse B, Brown LF, Van de Water L, Dvorak HF \& Senger DR 1992 Vascular permeability factor (vascular endothelial growth factor) gene is expressed differentially in normal tissues, macrophages, and tumors. Molecular Biology of the Cell 3 211-220.

Bevilacqua G, Sobel ME, Liotta LA \& Steeg PS 1989 Association of low nm23 RNA levels in human primary infiltrating ductal breast carcinomas with lymph node involvement and other histopathological indicators of high metastatic potential. Cancer Research 49 5185-5190.

Blobel GA \& Orkin SH 1996 Estrogen-induced apoptosis by inhibition of the erythroid transcription factor GATA-1. Molecular and Cellular Biology 16 1687-1694.

Bogin L \& Degani H 2002 Hormonal regulation of VEGF in orthotopic MCF7 human breast cancer. Cancer Research 62 1948-1951.

Bruhat A, Jousse C, Wang XZ, Ron D, Ferrara M \& Fafournoux P 1997 Amino acid limitation induces expression of CHOP, a CCAAT/enhancer binding protein-related gene, at both transcriptional and post-transcriptional levels. Journal of Biological Chemistry 272 17588-17593.

Calle EE, Miracle-McMahill HL, Thun MJ \& Heath CW Jr 1995 Estrogen replacement therapy and risk of fatal colon cancer in a prospective cohort of postmenopausal women. Journal of the National Cancer Institute 87 517-523.

Campbell-Thompson M, Lynch I J \& Bhardwaj B 2001 Expression of estrogen receptor (ER) subtypes and ERbeta isoforms in colon cancer. Cancer Research 61 632-640.

Chan SW \& Hong W 2001 Retinoblastoma-binding protein 2 (Rbp2) potentiates nuclear hormone receptor-mediated transcription. Journal of Biological Chemistry 276 28402-28412.

Choi SW \& Mason JB 2000 Folate and carcinogenesis an integrated scheme. Journal of Nutrition 130 129-132.

Coller HA, Grandori C, Tamayo P, Colbert T, Lander ES, Eisenman RN \& Golub TR 2000 Expression analysis with oligonucleotide microarrays reveals that MYC regulates genes involved in growth, cell cycle, signaling, and adhesion. PNAS 97 3260-3265.

Ellis LM, Liu W \& Wilson M 1996 Down-regulation of vascular endothelial growth factor in human colon carcinoma cell lines by antisense transfection decreases endothelial cell proliferation. Surgery $120871-878$

Foley EF, Jazaeri AA, Shupnik MA, Jazaeri O \& Rice LW 2000 Selective loss of estrogen receptor beta in malignant human colon. Cancer Research 60 245-248.

Ford D, Easton DF, Bishop DT, Narod SA \& Goldgar DE 1994 Risks of cancer in BRCA1-mutation carriers. Breast Cancer Linkage Consortium. Lancet 343 692-695.

Gautier F, Irminger-Finger I, Gregoire M, Meflah K \& Harb J 2000 Identification of an apoptotic cleavage product of BARD1 as an autoantigen: a potential factor in the antitumoral response mediated by apoptotic bodies. Cancer Research 60 6895-6900.

Grodstein F, Newcomb PA \& Stampfer MJ 1999 Postmenopausal hormone therapy and the risk of colorectal cancer: a review and meta-analysis. American Journal of Medicine 106 574-582.

Gryfe R, Swallow C, Bapat B, Redston M, Gallinger S \& Couture J 1997 Molecular biology of colorectal cancer. Ras and colon cancer. Current Problems in Cancer 21 233-300.

Gujuluva CN, Baek JH, Shin KH, Cherrick HM \& Park NH 1994 Effect of UV-irradiation on cell cycle, viability and the expression of p53, gadd153 and gadd45 genes in normal and HPV-immortalized human oral keratinocytes. Oncogene 9 1819-1827.

Haut M, Steeg P S, Willson J K \& Markowitz SD 1991 Induction of $n m 23$ gene expression in human colonic neoplasms and equal expression in colon tumors of high and low metastatic potential. Journal of the National Cancer Institute 83 712-716.

Hebert-Croteau N 1998 A meta-analysis of hormone replacement therapy and colon cancer in women. Cancer Epidemiology, Biomarkers and Prevention 7 653-659.
Jamora C, Dennert G \& Lee AS 1996 Inhibition of tumor progression by suppression of stress protein GRP78/BiP induction in fibrosarcoma B/C10 ME. PNAS 93 7690-7694.

Kawahara, K, Oyadomari S, Gotoh T, Kohsaka S, Nakayama H \& Mori M 2001 Induction of CHOP and apoptosis by nitric oxide in p53-deficient microglial cells. FEBS Letters 506 135-139.

Keim D, Hailat N, Melhem R, Zhu X X, Lascu I, Veron M, Strahler J \& Hanash SM 1992 Proliferation-related expression of p19/nm23 nucleoside diphosphate kinase. Journal of Clinical Investigation 89 919-924.

Kuiper GG, Carlsson B, Grandien K, Enmark E, Haggblad J, Nilsson S \& Gustafsson JA 1997 Comparison of the ligand binding specificity and transcript tissue distribution of estrogen receptors alpha and beta. Endocrinology 138 863-870.

Lin KH, Wang WJ, Wu YH \& Cheng SY 2002 Activation of antimetastatic Nm23-H1 gene expression by estrogen and its alpha-receptor. Endocrinology 143 467-475.

Lobenhofer EK, Bennett L, Cable PL, Li L, Bushel PR Afshari CA 2002 Regulation of DNA replication fork genes by 17 beta-estradiol. Molecular Endocrinology 16 1215-1229.

Luethy JD, Fargnoli J, Park JS, Fornace AJ Jr \& Holbrook NJ 1990 Isolation and characterization of the hamster gadd153 gene. Activation of promoter activity by agents that damage DNA. Journal of Biological Chemistry 265 16521-16526.

Maclean KN, McKay IA \& Bustin SA 1998 Differential effects of sodium butyrate on the transcription of the human TIS11 family of early-response genes in colorectal cancer cells. British Journal of Biomedical Science 55 184-191.

McCullough KD, Martindale JL, Klotz LO, Aw TY \& Holbrook NJ 2001 Gadd153 sensitizes cells to endoplasmic reticulum stress by down-regulating Bcl2 and perturbing the cellular redox state. Molecular and Cellular Biology 21 1249-1259.

Maytin EV, Ubeda M, Lin JC \& Habener JF 2001 Stress-inducible transcription factor $\mathrm{CHOP} /$ gadd153 induces apoptosis in mammalian cells via p38 kinase-dependent and -independent mechanisms. Experimental Cell Research 267 193-204.

Muramatsu M \& Inoue S 2000 Estrogen receptors: how do they control reproductive and nonreproductive functions? Biochemical and Biophysical Research Communications 270 1-10.

Nilsen J, Mor G \& Naftolin F 2000 Estrogen-regulated developmental neuronal apoptosis is determined by estrogen receptor subtype and the Fas/Fas ligand system. Journal of Neurobiology 43 64-78.

Qiu Y, Waters CW, Lewis AE, Langman MJS \& Eggo MC 2002 Oestrogen-induced apoptosis in colonocytes expressing oestrogen receptor $\beta$. Journal of Endocrinology 174 369-377.

Ramsay G 1998 DNA chips state-of-the art. Nature Biotechnology 16 40-44.

Roccato E, Miranda C, Ranzi V, Gishizki M, Pierotti MA \& Reco A 2002 Biological activity of the thyroid TRK-T3 oncogenes requires signalling through Shc. British Journal of Cancer 87 645-653.

Ron D \& Habener JF 1992 CHOP, a novel developmentally regulated nuclear protein that dimerizes with transcription factors $\mathrm{C} / \mathrm{EBP}$ and LAP and functions as a dominant-negative inhibitor of gene transcription. Genes and Development 6 439-453.

Russo J, Tahin Q, Lareef MH, Hu YF \& Russo IH 2002 Neoplastic transformation of human breast epithelial cells by estrogens and chemical carcinogens. Environmental and Molecular Mutagenesis 39 254-263.

Shibata H, Spencer TE, Onate SA, Jenster G, Tsai SY, Tsai MJ \& O'Malley BW 1997 Role of co-activators and co-repressors in the mechanism of steroid/thyroid receptor action. Recent Progress in Hormone Research 52 141-164.

Shimada T, Kojima K, Yoshiura K, Hiraishi H \& Terano A 2002 Characteristics of the peroxisome proliferator activated receptor gamma (PPARgamma) ligand induced apoptosis in colon cancer cells. Gut 50 658-664.

Smirnoff P, Liel Y, Gnainsky J, Shany S \& Schwartz B 1999 The protective effect of estrogen against chemically induced murine 
colon carcinogenesis is associated with decreased $\mathrm{CpG}$ island methylation and increased mRNA and protein expression of the colonic vitamin D receptor. Oncology Research 11 255-264.

Song RX, Mor G, Naftolin F, McPherson RA, Song J, Zhang Z, Yue W, Wang J \& Santen RJ 2001 Effect of long-term estrogen deprivation on apoptotic responses of breast cancer cells to 17 beta-estradiol. Journal of the National Cancer Institute 93 1714-1723.

Steeg PS, Bevilacqua G, Kopper L, Thorgeirsson UP, Talmadge JE, Liotta LA \& Sobel ME 1988 Evidence for a novel gene associated with low tumor metastatic potential. Journal of the National Cancer Institute 80 200-204.

Stover PJ, Chen LH, Suh JR, Stover DM, Keyomarsi K \& Shane B 1997 Molecular cloning, characterization, and regulation of the human mitochondrial serine hydroxymethyltransferase gene. Journal of Biological Chemistry 272 1842-1848.

Szelei J, Soto AM, Geck P, Desronvil M, Prechtl NV, Weill BC \& Sonnenschein C 2000 Identification of human estrogen-inducible transcripts that potentially mediate the apoptotic response in breast cancer. Journal of Steroid Biochemistry and Molecular Biology $\mathbf{7 2}$ $89-102$.

Takahashi Y, Kitadai Y, Bucana CD, Cleary KR \& Ellis LM 1995 Expression of vascular endothelial growth factor and its receptor, $\mathrm{KDR}$, correlates with vascularity, metastasis, and proliferation of human colon cancer. Cancer Research 55 3964-3968.
Takahashi Y, Tucker SL, Kitadai Y, Koura AN, Bucana CD, Cleary KR \& Ellis LM 1997 Vessel counts and expression of vascular endothelial growth factor as prognostic factors in node-negative colon cancer. Archives of Surgery 132 541-546.

Ubeda M \& Habener JF 2000 CHOP gene expression in response to endoplasmic-reticular stress requires NFY interaction with different domains of a conserved DNA-binding element. Nucleic Acids Research 28 4987-4997.

Warren RS, Yuan H, Matli MR, Gillett NA \& Ferrara N 1995 Regulation by vascular endothelial growth factor of human colon cancer tumorigenesis in a mouse model of experimental liver metastasis. Journal of Clinical Investigation 95 1789-1797.

Warren RS, Yuan H, Matli MR, Ferrara N \& Donner DB 1996 Induction of vascular endothelial growth factor by insulin-like growth factor 1 in colorectal carcinoma. Journal of Biological Chemistry $27129483-29488$.

Zhang CC \& Shapiro DJ 2000 Activation of the p38 mitogen-activated protein kinase pathway by estrogen or by 4-hydroxytamoxifen is coupled to estrogen receptor-induced apoptosis. Journal of Biological Chemistry 275 479-486.

Received in final form 13 February 2004

Accepted 18 February 2004 